\title{
Electrical signalling properties of oligodendrocyte precursor cells
}

\author{
YAMINA BAKIRI ${ }^{1}$, DAVID ATTWELL ${ }^{1}$ AND RAGNHILDUR KARÁDÓTTIR ${ }^{2}$
}

\begin{abstract}
Oligodendrocyte precursor cells (OPCs) have become the focus of intense research, not only because they generate myelinforming oligodendrocytes in the normal CNS, but because they may be suitable for transplantation to treat disorders in which myelin does not form or is damaged, and because they have stem-cell-like properties in that they can generate astrocytes and neurons as well as oligodendrocytes. In this article we review the electrical signalling properties of OPCs, including the synaptic inputs they receive and their use of voltage-gated channels to generate action potentials, and we describe experiments attempting to detect output signalling from OPCs. We discuss controversy over the existence of different classes of OPC with different electrical signalling properties, and speculate on the lineage relationship and myelination potential of these different classes of OPC. Finally, we point out that, since OPCs are the main proliferating cell type in the mature brain, the discovery that they can develop into neurons raises the question of whether more neurons are generated in the mature brain from the classical sites of neurogenesis in the subventricular zone of the lateral ventricle and the hippocampal dentate gyrus or from the far more widely distributed OPCs.
\end{abstract}

Keywords: Myelin, OPC, NG2, stem cell, neuron

\section{INTRODUCTION}

Oligodendrocyte precursor cells (OPCs) transform into myelinating oligodendrocytes during development (Nishiyama et al., 2002), but are also present in the adult CNS where they comprise $\sim 5 \%$ of the cells and are the main proliferating cell type (Horner et al., 2000; Stallcup, 2002; Dawson et al., 2003). Damage to oligodendrocyte precursors, leading to reduced myelination, contributes to mental and physical impairment in periventricular leukomalacia (pre- or perinatal white matter injury leading to cerebral palsy; Volpe, 2001). Adult OPCs may form new myelinating oligodendrocytes in multiple sclerosis, and in brain or spinal cord injury (Levine, 1994; Gensert and Goldman, 1997; Keirstead et al., 1998; McTigue et al., 2001; Levine et al., 2001; Horner et al., 2002), and OPC transplants could serve as a basis for therapeutic remyelination (Windrem et al., 2008; Moreno-Manzano et al., 2009). This article will focus on the electrical signalling properties of OPCs which, as we will describe below, may play a crucial role in their development and their myelination of axons.

\section{DEFINING DPCS}

In the next section we will review several papers suggesting that OPCs are not a homogenous set of cells, but fall into at least two classes. To establish the range of properties of OPCs, it is essential to have criteria to define which cells are OPCs; so we will preface our review by examining the techniques available for doing this, and their advantages and pitfalls.

Corresponding author:

D. Attwell

Email: d.attwell@ucl.ac.uk
Classically, OPCs have been defined antigenically, both in culture and in situ, by their expression of the proteoglycan NG2 (Nishiyama et al., 1996), the growth factor receptor PDGFR $\alpha$ (Pringle et al., 1992) and the transcription factor Olig2 (Ligon et al., 2004, 2006). When recording the electrical properties of OPCs in brain slices two broad approaches have been employed. One method is to record from the cells and then use immunocytochemistry after recording to check whether OPC markers such as NG2, PDGFR $\alpha$ or Olig2 are expressed (Bergles et al., 2000; Káradóttir et al., 2005, 2008; Káradóttir and Attwell, 2006; Kukley et al., 2007). As a variant of this approach, some antigens can be labelled in living cells, and thus used to select cells for recording, with an antibody binding to an extracellular epitope such as NG2 (Káradóttir et al., 2008). Alternatively, expression of a fluorescent protein like GFP or DsRed, under control of an OPC-specific promoter, can be used to select cells (Belachew et al., 2001; Chittajallu et al., 2004; Ziskin et al., 2007).

Both of these methods have the advantage of not relying solely on location in the brain, cell morphology or developmental stage of the animal to define OPCs, but both have problems. Immunocytochemistry after recording requires that the electrode can be removed from the cell without destroying it. This manoeuvre requires both practice and luck, so that only a proportion of cells recorded from can be positively identified with antibodies. Consequently the remainder must be assumed to be OPCs on the basis of their dye-filled morphology, observed while recording, being similar to that seen for the cells that are successfully recovered for immunocytochemistry.

Genetic labelling of cell types also suffers from three potential problems. First, commonly, the construct expressing the fluorescent label is not knocked into the endogenous gene locus for the protein whose expression is controlled by the OPC-specific promoter, but a transgene that inserts randomly into the genome is used instead. In this case, because 
expression can be influenced by DNA sequence surrounding the transgene integration site, the label may be expressed ectopically in cells not actually expressing the protein. For example, the GFAP-GFP mouse reported by Matthias et al. (2003) showed GFP expression not only in GFAP-expressing astrocytes but also, more weakly, in another cell class (termed 'glutamate receptor expressing astrocytes' at the time) which express the mouse homologue of NG2 (Jabs et al., 2005) and which are therefore, we suggest, what others call OPCs (see also Serrano et al., 2008). Interestingly, Schools et al. (2003) and Zhou et al. (2000) reported that some NG2-expressing OPCs produce mRNA for GFAP (showing that the GFAP promoter is active) but they do not express the protein (i.e. they are not labelled by antibody to GFAP, presumably because translation does not occur or GFAP breakdown is rapid). This may suggest that the misleading expression of GFP from the GFAP promoter in some OPCs (Matthias et al., 2003; Jabs et al., 2005) may reflect an inadequate control of synthesis or degradation of the exogenous protein GFP compared to that of the endogenous GFAP. Second, if the construct is knocked into the endogenous locus of a protein controlled by an OPC-specific promoter, this usually disables the target gene leaving the mouse hemizygous for that gene. It is then possible (as noted by Dimou et al., 2008) that the resulting haplo-insufficiency, caused by the absence of protein produced from that locus, may perturb the system being studied. Third, a fluorescent marker produced under the control of a developmentally down-regulated promoter, such as that for NG2, may persist in the cell even after the promoter activity has ceased and the cell has moved on to a later lineage stage, making it hard to be sure which fluorescent cells are truly at the OPC stage.

In addition to labelling approaches, it has been suggested that one can use the electrophysiologically recorded membrane currents of the cell to identify OPCs, making the assumption that glial precursor cells express voltage-gated currents (Borges et al., 1994; Kukley et al., 2007). However, if the full range of membrane currents that exist in different classes of OPC is not fully known, this might result in only a subset of OPCs being studied.

\section{DIFFERENT TYPES DF DPC}

Although OPCs have been historically viewed as a homogenous class of cell, comprising just one stage of oligodendrocyte development, recent work has suggested that these cells are more complex than previously thought.

When EGFP is expressed under the control of the promoter for proteolipid protein (PLP, a myelin protein expressed only in oligodendrocytes), two populations of proliferating $\mathrm{NG}_{2}$-expressing cells were revealed in the neocortex, one that expresses EGFP and one that does not (Mallon et al., 2002). This result was suggested by Mallon et al. (2002) to indicate that there were two types of $\mathrm{NG}_{2}$-expressing OPCs of similar morphology, one which turned into myelinating oligodendrocytes (which need to express PLP to make myelin) and the other (lacking PLP expression) which may become the OPCs found in the adult CNS after myelination is complete. Alternative interpretations might be that the cells lacking EGFP expression are either simply OPCs that do not yet express PLP at a high level (because they are not yet myelinating axons), or are leaving the oligodendrocyte lineage to become astrocytes or neurons, as discussed below (Dimou et al., 2008; Rivers et al., 2008; Zhu et al., 2008a,b).

In contrast, Horner et al. (2002) suggested the presence of two morphologically different classes of NG2-positive cells in the adult CNS: bipolar cells that take up BrdU more readily (and so are dividing) and multipolar cells that take up BrdU less readily. Likewise, other studies have shown that $25-50 \%$ of the $\mathrm{NG}_{2}$ - or PDGFR $\alpha$-expressing cells either take up BrdU or co-label for proliferation markers such as Ki67 or PCNA (Aguirre et al., 2004; Kukley et al., 2008; Rivers et al., 2008; Fig. 1J).

Two classes of OPC may also be involved in the response to CNS injury. Keirstead et al. (1998) suggested that after spinal cord damage the OPCs fall into two classes, a class that proliferates and a class that does not. Similarly, when EGFP was expressed via the promoter for 2,3 cyclic nucleotide 3-phosphodiesterase (CNP), two types of NG2-expressing OPCs were detected in response to spinal cord injury, one of which was bipolar, expressed EGFP, proliferated earlier and was suggested to turn into new oligodendrocytes, while the other was multipolar and did not form mature oligodendrocytes (Lytle et al., 2009).

All of the studies above were based purely on labelling the cells but, when defining OPCs by their dye-fill morphology and their expression of $\mathrm{NG}_{2}$ and Olig2, OPCs in the white matter of the rat cerebellum (Fig. 1A-F) and corpus callosum (Fig. $1 \mathrm{G}, \mathrm{H}$ ) were also found to fall into two distinct electrophysiological classes (Káradóttir et al., 2008). One of these classes expresses voltage-gated $\mathrm{Na}^{+}$and delayed rectifier $\mathrm{K}^{+}$ channels, and the other expresses no $\mathrm{Na}^{+}$current and very little $\mathrm{K}^{+}$current but shows an approximately timeindependent $I-V$ relation for which the conductance is roughly independent of voltage. The approximately ohmic mean steady-state $I-V$ relation for such cells (hereafter termed ohmic OPCs), shown in fig. $2 \mathrm{G}$ of Káradóttir et al. (2008), contrasts with the strongly outwardly rectifying steady-state $I-V$ relation found for the cells expressing voltage-gated currents (fig. $2 \mathrm{G}$ of Káradóttir et al., 2008). At present it is unclear how these two OPC classes (which are apparently morphologically indistinguishable) relate to the two classes reported by Mallon et al. (2002) and Horner et al. (2000). The segregation of OPCs into two electrically distinct classes has since been confirmed to exist for OPCs in two separate transgenic mice expressing YFP under the control of the oligodendrocyte-specific Sox10 or PDGFR $\alpha$ promoters (Clarke et al., 2009).

Previous electrophysiological studies did not explicitly report the ohmic class of OPC in the white matter (Kukley et al., 2007; Ziskin et al., 2007) or in the grey matter (Bergles et al., 2000; Lin and Bergles, 2004; Jabs et al., 2005; Ge et al., 2006). However, Karram et al. (2008) found some grey matter OPCs expressed almost no voltagegated $\mathrm{Na}^{+}$current (left cell in their fig. 8b) and Schools et al. (2003) found that two out of ten P20-26 OPCs in the hippocampus had no detectable voltage-gated $\mathrm{Na}^{+}$current. Furthermore, there are two possible explanations for the previous lack of reporting of the ohmic class of OPC in the white matter. First, Kukley et al. (2007) selected OPCs 'on the basis of their characteristic expression pattern of voltage-gated ion channels', i.e. apparently excluding the ohmic class of OPCs which lack voltage-gated channels. Second, it is plausible that Ziskin et al. (2007) did not report the ohmic OPCs in 


\section{cerebellar white matter}
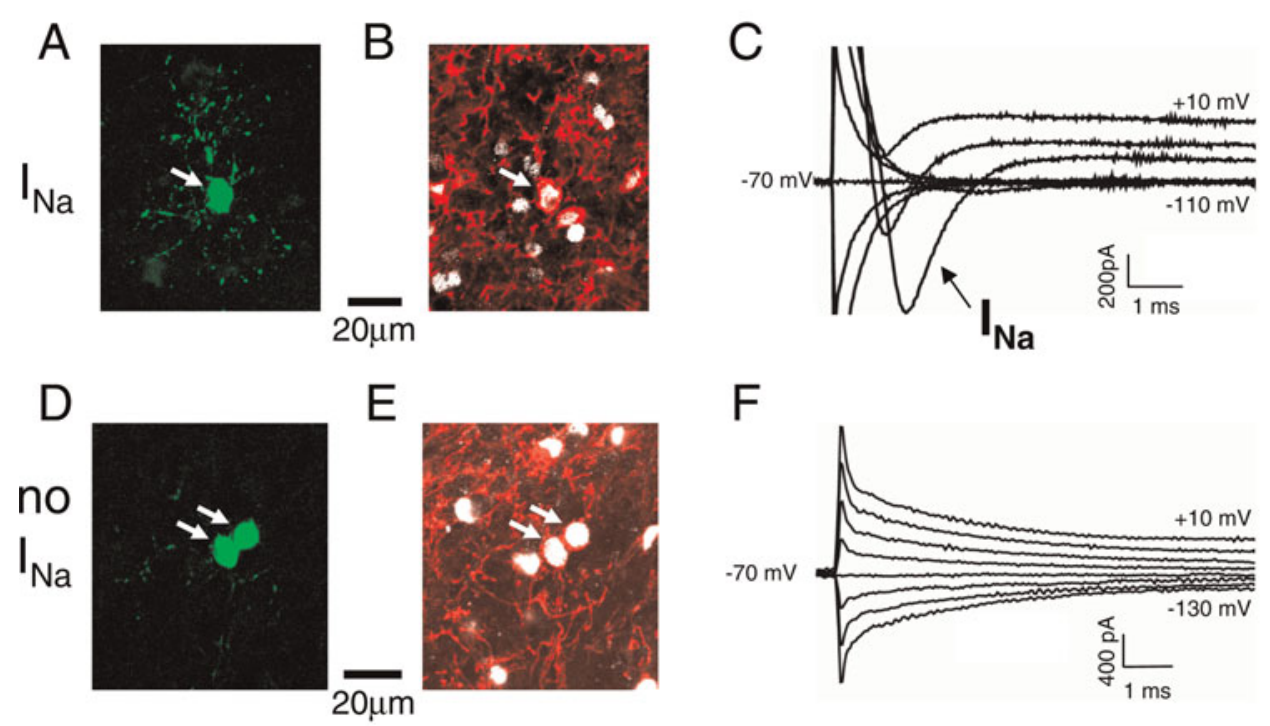

$\mathrm{F}$
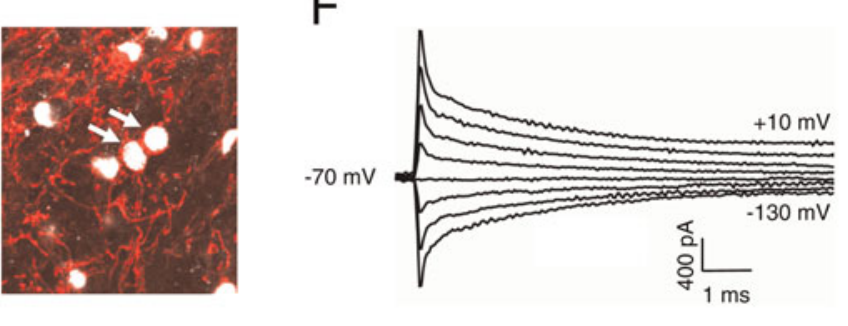

\section{corpus callosum}

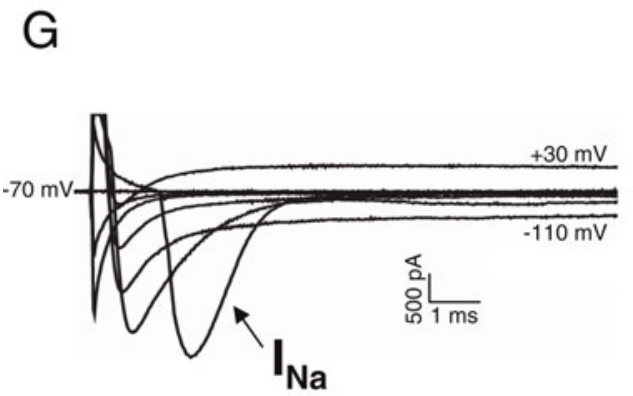

$\mathrm{H}$

\section{cerebellar white matter}
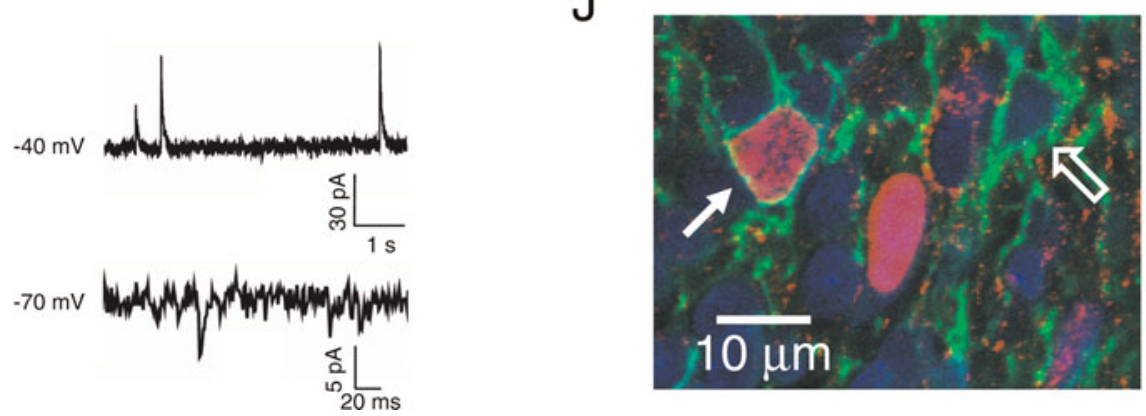

Fig. 1. NG2-expressing OPCs fall into two classes in the white matter of the cerebellum (A-F) and corpus callosum (G,H). (A) Lucifer yellow fill of a cerebellar OPC expressing $\mathrm{I}_{\mathrm{Na}}$ (the cell in figs $2 e$ and 3a of Káradóttir et al., 2008). (B) Same cell (arrows) labelled after recording for NG2 (red) and Olig2 (white) to verify the cell's identity as an OPC. (C) Membrane current of the cell in A and B in response to voltage steps from $-70 \mathrm{mV}$ in increments of $20 \mathrm{mV}$. (D-F) As for A-C but for an OPC lacking $\mathrm{I}_{\mathrm{Na}}$ apparently in the process of cell division. (D) Lucifer yellow fill of the patch-clamped OPC reveals that two closely apposed cells were filled (arrows). (E) Labelling of the cells in D for NG2 (red) and Olig2 (white) to verify their identity as OPCs. (F) Membrane currents evoked in this pair of cells by voltage steps from $-70 \mathrm{mV}$ in $20 \mathrm{mV}$ increments. Same cells as in fig $3 \mathrm{C}$ of Káradóttir $e$ et al. (2008). Fitting a two exponential decay to the unfiltered capacity current transient showed that the series resistance was $19.5 \mathrm{M} \Omega$. (G) Membrane current of a corpus callosal OPC expressing $\mathrm{I}_{\mathrm{Na}}$ in response to voltage steps in $20 \mathrm{mV}$ increments from $-70 \mathrm{mV}$. (H) As for $\mathrm{G}$ but for a cell lacking $\mathrm{I}_{\mathrm{Na}}$. (I) Excitatory and inhibitory synaptic currents in an OPC in the cerebellar white matter. IPSCs (outward currents) and EPSCs (inward currents) were recorded at $-44 \mathrm{mV}$ ( $\mathrm{E}_{\mathrm{Cl}}$ was $\left.-87 \mathrm{mV}\right)$. (J) Labelling of the cerebellar white matter with antibody to NG2 (green), antibody to the proliferation marker Ki67 (red) and for nuclei (DAPI, blue), showing two OPCs, one expressing Ki67 (solid arrow) and one not (open arrow).

NG2-DsRed mice either because the DsRed label does not label the ohmic OPCs well or perhaps because any ohmic cells recorded were excluded from consideration on the grounds that the fluorescent label might have outlasted the OPC stage of oligodendrocyte development (see above).
Since mature oligodendrocytes do not express detectable voltage-gated $\mathrm{Na}^{+}$current, an obvious possibility is that the ohmic OPCs, despite their expression of $\mathrm{NG}_{2}$ (Káradóttir et al., 2008), are at a post-mitotic stage in the oligodendrocyte lineage, differentiating into oligodendrocytes and thus not 
A

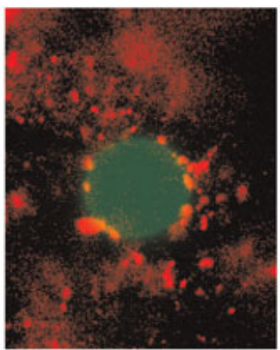

C $\overline{20 \mu \mathrm{m}}$
B
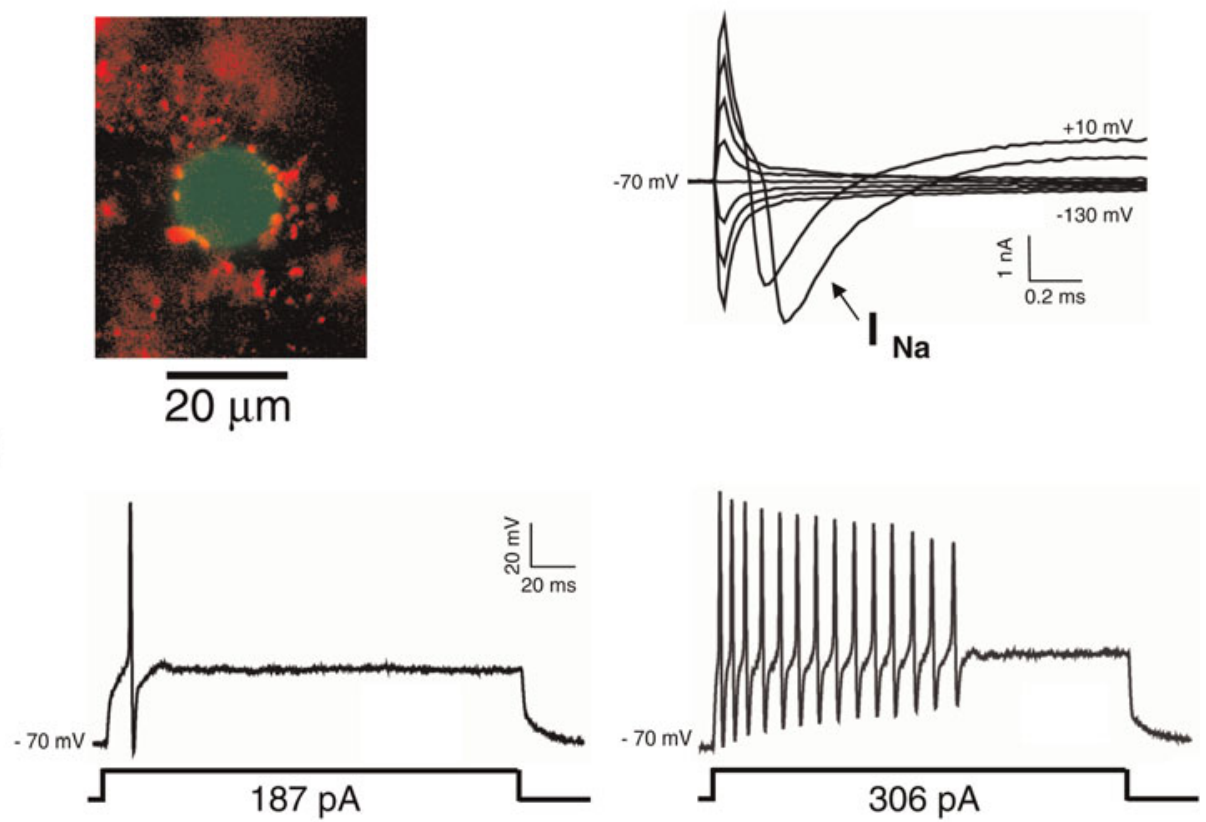

$\mathrm{E}$

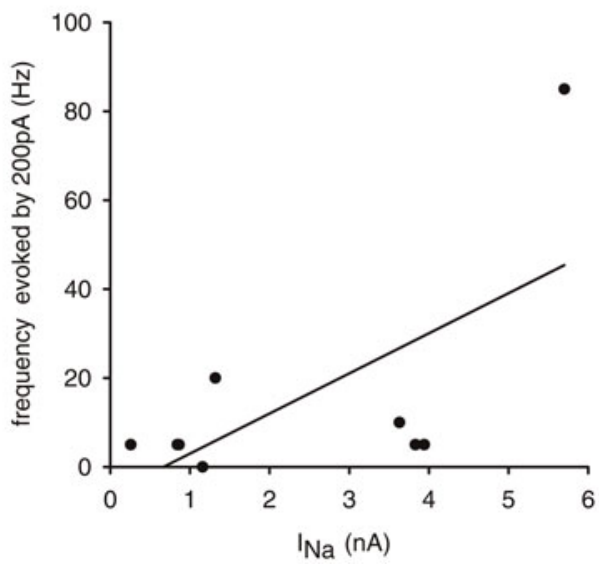

Fig. 2. $\mathrm{Na}^{+}$channel expressing OPCs can generate action potentials. (A) OPC in the cerebellar white matter live-labelled with an antibody to NG2 (red) as in Káradóttir et al. (2008), and showing also Lucifer yellow (green) in the soma after the electrode was removed from the cell. (B) Membrane current evoked by $20 \mathrm{mV}$ steps from $-70 \mathrm{mV}$ in $20 \mathrm{mV}$ increments. (C) Action potentials evoked in current clamp mode by injection of 187 and $306 \mathrm{pA}$. (D) Dependence of the threshold current needed to evoke an action potential on the input resistance of the cell (each point is one cell; line is a best-fit linear regression through the data, which has a slope significantly different from zero, $P=0.014$ from the regression F-statistic). (E) Dependence of the frequency of action potentials evoked by a 200 pA current step (averaged over $200 \mathrm{~ms}$ from the start of the step) on the magnitude of the cell's $\mathrm{Na}^{+}$current evoked by depolarization from -70 to $-10 \mathrm{mV}$ (the linear regression has a slope significantly different from zero, $P=0.05$ ).

true precursors. Although this is a possibility, which needs to be resolved by further labelling with proliferation markers, the observation of ohmic cells apparently in the process of dividing (Fig. 1D-F, and see Káradóttir et al., 2008) argues against this idea.

\section{SYNAPTIC INPUT TD DPCS}

The discovery that OPCs in the grey matter (Bergles et al., 2000; Lin and Bergles, 2004; Jabs et al., 2005) and white matter (Káradóttir et al., 2005; Kukley et al., 2007; Ziskin et al., 2007) receive synaptic input shows that these cells are actively sensing the neuronal activity in the local environment, perhaps providing a partial explanation for earlier work showing that OPC differentiation and myelination depend on neural activity (Demerens et al., 1996). The synaptic input to OPCs in both the grey and white matter can be either glutamatergic or GABAergic (Bergles et al., 2000; Lin and Bergles, 2004; Káradóttir et al., 2008), but either type of input depolarizes OPCs, since the chloride concentration is high in OPCs (Lin and Bergles, 2004).

In the white matter of the corpus callosum the synaptic input to OPCs is from unmyelinated axons (Kukley et al., 2007; Ziskin et al., 2007), suggesting that this synaptic transmission may serve as a signal from active axons to OPCs to instruct them to myelinate the axons. The initial phase of this process may be a suppression of proliferation of OPCs induced by the 
glutamate or (in other brain regions) GABA released onto them, since activation of glutamate receptors is known to suppress OPC proliferation (Yuan et al., 1998) and GABA suppresses proliferation of neurons (LoTurco et al., 1995). However, the presence of synaptic input does not immediately suppress proliferative activity, because OPCs that receive synapses retain those synapses through the process of cell division to the daughter cell stage both in white matter (Kukley et al., 2008) and in grey matter (Ge et al., 2009).

In the corpus callosum, where almost all the axons are excitatory, $\mathrm{Na}^{+}$channel expressing OPCs receive excitatory synaptic input from 11 to 140 unmyelinated axons (Kukley et al., 2007; Ziskin et al., 2007). In the cerebellum synaptic input was recorded far more readily in $\mathrm{Na}^{+}$channel expressing OPCs than in ohmic OPCs (Káradóttir et al., 2008), and could be either an inward glutamatergic current or an outward (under the low $[\mathrm{Cl}]_{\mathrm{i}}$ conditions used) GABAergic current (Fig. 1I). The spontaneous frequency of either kind of input was invariably less than $2 \mathrm{~Hz}$. The spontaneous glutamatergic synaptic currents probably reflect spontaneous vesicular release from excitatory mossy or climbing fibres (which are thought to not display spontaneous action potentials in cerebellar slices), while the GABAergic synaptic currents may reflect action potentials in Purkinje cells, although it is surprising that the frequency of IPSCs was so low since Purkinje cells in slices are thought to fire spontaneously at $\sim 40 \mathrm{~Hz}$ (Häusser and Clark, 1997). At present it is unknown whether individual oligodendrocytes myelinate purely glutamatergic or purely GABAergic axons, or whether the same oligodendrocyte can myelinate both.

\section{SIGNAL PRDCESSING BY DPCS}

OPCs expressing both $\mathrm{NG}_{2}$ and voltage-gated $\mathrm{Na}^{+}$currents in the cerebellar white matter can generate regenerative action potentials when depolarized (Fig. 2A-C; Káradóttir et al., 2008). Previously it had been suggested that oligodendrocytes in the subcortical white matter of mice were less excitable than those in the neocortical grey matter, $\sim 30 \%$ of which show a single 'immature' spike on depolarization (Chittajallu et al., 2004; Ge et al., 2008), although some have reported that grey matter OPCs are incapable of generating action potentials (Bergles et al., 2000; Lin and Bergles, 2004). In our experiments the likelihood of generating action potentials varied with the magnitude of the voltage-gated sodium conductance and with the input resistance of the cell (which can be adversely reduced by the conductance of the seal between the electrode and the cell membrane, see e.g. Newell and Schlichter (2005) who found that microglia with an apparent input resistance of $\sim 2 \mathrm{G} \Omega$ had a true membrane resistance of $\sim 8 \mathrm{G} \Omega$ ). The threshold current needed to evoke an action potential varied roughly inversely with the input resistance at the resting potential (Fig. 2D), while the frequency of action potentials generated by a $200 \mathrm{pA}$ current step was roughly correlated with the magnitude of the $\mathrm{Na}^{+}$current seen on depolarizing from -70 to $-10 \mathrm{mV}$ (Fig. $2 \mathrm{E}$ ).

Action potentials were not observed by Ziskin et al. (2007) in NG2-DsRed mouse white matter OPCs expressing voltagegated $\mathrm{Na}^{+}$channels. However, in preliminary work on Sox10-GFP and PDGFR $\alpha$-GFP mice, we do find that a small proportion of OPCs show regenerative depolarizations generated by voltage-gated $\mathrm{Na}^{+}$current: this proportion may be smaller than in rat OPCs because the magnitude of the $\mathrm{Na}^{+}$current is smaller in mouse than in rat OPCs (Clarke et al., 2009), and shunting by the seal between the electrode and the cell is therefore more important in determining the excitability of the cell.

Whether or not full action potentials are produced, the voltage-gated $\mathrm{Na}^{+}$current present in some OPCs is likely to amplify excitatory (glutamatergic or GABAergic) synaptic inputs. What could the function of this regenerative depolarization of OPCs be? The membrane depolarization and sodium influx mediated by the voltage-gated $\mathrm{Na}^{+}$channels will raise the intracellular sodium concentration in the OPCs, which may block membrane $\mathrm{K}^{+}$channels and inhibit OPC proliferation (Knutson et al., 1997). Regulation of proliferation could thus be different in the two classes of OPC which express, and which do not express, voltage-gated $\mathrm{Na}^{+}$channels. In addition, the inward current through voltage-gated $\mathrm{Na}^{+}$channels is likely to raise the calcium concentration in OPCs, both by opening voltage-gated $\mathrm{Ca}^{2+}$ channels (Verkhratsky et al., 1990; Blankenfeld et al., 1992; Kirischuk et al., 1995) and by raising $\left[\mathrm{Na}^{+}\right]_{\mathrm{i}}$ and reversing $\mathrm{Na}^{+} / \mathrm{Ca}^{2+}$ exchange (Chen et al., 2007). The resulting rise of $\left[\mathrm{Ca}^{2+}\right]_{\mathrm{i}}$ might have a cell intrinsic role, regulating OPC development, or it could serve (as in neurons) to trigger exocytosis of substances from OPCs.

The possibility that OPCs have functions other than simply becoming oligodendrocytes is suggested by the fact that OPCs are found in some brain areas (such as the cerebellar molecular layer in rats) where no myelination occurs. Thus, it is conceivable that OPCs have output synapses as well as input synapses.

\section{DD DPCS HAVE $\square U T P U T$ SYNAPSES?}

As one approach to trying to detect output signalling from OPCs, we loaded cerebellar slices with calcium-sensing dyes, and then depolarized white matter OPCs from -70 to $-20 \mathrm{mV}$ (close to the voltage at which voltage-gated $\mathrm{Ca}^{2+}$ channels generate their maximum $\mathrm{Ca}^{2+}$ influx) for $100 \mathrm{~ms}$ (or applied repeated $1 \mathrm{~ms}$ depolarizations to $-20 \mathrm{mV}$ at $100 \mathrm{~Hz}$ for $100 \mathrm{~ms})$. We then searched for a rise of $\left[\mathrm{Ca}^{2+}\right]$ concentration in surrounding cells occurring at the time of OPC depolarization, which might reflect exocytosis of a transmitter from the OPC onto other cells nearby. OPC processes reach $\sim 30 \mu \mathrm{m}$ from the cell (Káradóttir et al., 2008) and processes from cells that might receive input from OPCs are likely to be of at least a similar length, so surrounding cells were studied both within the $60 \mu \mathrm{m}$ distance that could be reached by the sum of these process lengths, as well as further away in case longer processes mediate signalling from OPCs to other cells. Although many cells in the white and grey matter responded with a rise of $\left[\mathrm{Ca}^{2+}\right]_{\mathrm{i}}$ to a rise of $\left[\mathrm{K}^{+}\right]_{\mathrm{o}}$ or application of kainate (not shown), no convincing change in $\left[\mathrm{Ca}^{2+}\right]_{\mathrm{i}}$ in glial cells in the surrounding white matter (Fig. $3 \mathrm{~A}, \mathrm{~B}$ ) was evoked by OPC depolarization, and nor was a change seen in neurons and astrocytes in the nearby grey matter (Fig. $3 \mathrm{C}, \mathrm{D}$ ). This experiment was performed 29 times depolarizing a sodium channel expressing $\mathrm{OPC}$ and 3 times depolarizing a sodium channel lacking cell, and for each experiment more than ten calcium-dye-loaded cells in the vicinity were studied. Interpretation of the data was complicated by the occurrence of spontaneous $\left[\mathrm{Ca}^{2+}\right]_{i}$ elevations in some cells: sometimes, when a cell seemed to respond to the depolarization with a $\left[\mathrm{Ca}^{2+}\right]_{\mathrm{i}}$ rise, the previous 
A

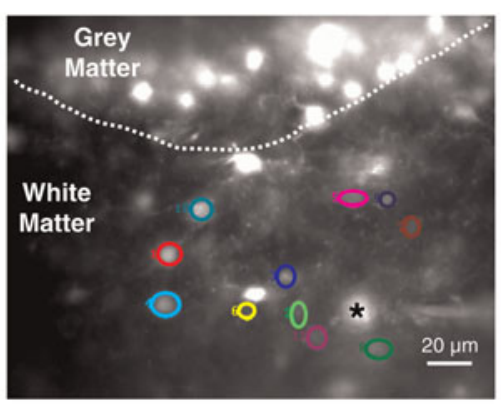

C

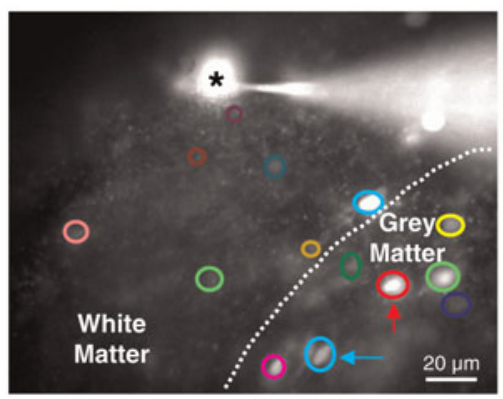

$\mathrm{B}$

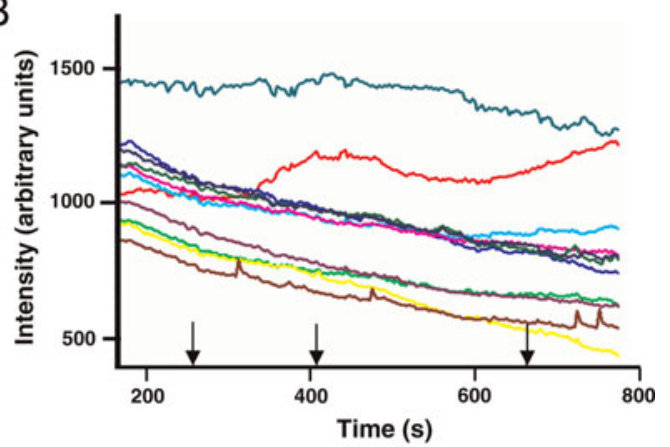

D

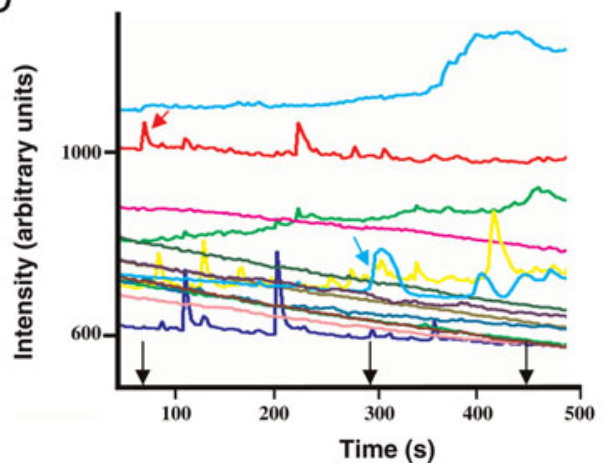

Fig. 3. Testing for whether depolarization of OPCs to $-20 \mathrm{mV}$ for $100 \mathrm{~ms}$ evokes a $\left[\mathrm{Ca}^{2+}\right]_{\mathrm{i}}$ rise in the surrounding white matter cells $(\mathrm{A}, \mathrm{B})$ or nearby grey matter cells (C,D) loaded with the AM ester of the $\mathrm{Ca}^{2+}$-sensitive dye Fluo-4. (A) Many cells in this slice that were loaded with Fluo-4 were located in the white matter. The patch-clamped cell is represented with an asterisk; the attached electrode is barely visible to the right. (B) The fluorescence of Fluo-4, in the cells labelled with circles in A, over time. The colours of the traces refer to the regions on panel A. The cells' $\left[\mathrm{Ca}^{2+}\right]_{\mathrm{i}}$ did not respond to depolarization of the patch-clamped cell (from -70 to $-20 \mathrm{mV}$ for $100 \mathrm{~ms}$, arrows). (C) Fluo-4-loaded cells located in the grey and white matter. The patch-clamped cell is represented with an asterisk. (D) The graph shows changes in Fluo-4 fluorescence over time. The colours of the trace refer to the regions of interest shown in C. Note that most of the cells show spontaneous calcium concentration changes. Depolarization of the patch-clamped cell (from -70 to $-20 \mathrm{mV}$ for $100 \mathrm{~ms}$, arrows) did not reproducibly trigger $\left[\mathrm{Ca}^{2+}\right]_{\mathrm{i}}$ changes in any cell: although the cells labelled with blue and red arrows (in $\mathrm{C}$ ) showed an increase in calcium around the times of, respectively, the first and second depolarization (arrows in D), no $\left[\mathrm{Ca}^{2+}\right]_{\mathrm{i}}$ change was observed in these cells after the other depolarizations.

and/or the next depolarization were not able to trigger any change in the $\left[\mathrm{Ca}^{2+}\right]_{i}$ of the cell (Fig. $3 \mathrm{D}$ ), suggesting that the $\left[\mathrm{Ca}^{2+}\right]_{i}$ rise was due to spontaneous activity of the cells.

We have, therefore, found no evidence for output synapses from OPCs. However, only the somata of cells were well loaded with the calcium-sensitive dye, so we cannot rule out the notion that the depolarization of OPCs triggered a change of $\left[\mathrm{Ca}^{2+}\right]_{\mathrm{i}}$ solely in the processes of neighbouring cells, and furthermore it is possible that transmitters were released from the OPC but did not act on receptors that raise $\left[\mathrm{Ca}^{2+}\right]_{\mathrm{i}}$ (for example, there may be metabotropic signalling via receptors altering cAMP levels, or activation of receptors gating channels that are not calcium permeable).

In the absence of detectable output signals from OPCs, we tentatively suggest that the electrical signals they receive and generate have a cell intrinsic role, regulating the development of OPCs and their switch from being precursors to carrying out myelination of axons.

\section{TWD TYPES DF DPC, TWD TYPES DFMYELINATION?}

Action potentials in axons are thought to regulate OPC development via multiple mechanisms.

Action potential-evoked PDGF release stimulates OPC proliferation (Barres and Raff, 1993), yet action potentials in unmyelinated excitatory fibres will also release glutamate onto OPCs (Kukley et al., 2007; Ziskin et al., 2007) which inhibits proliferation (Yuan et al., 1998). Perhaps these mechanisms operate on different spatial scales, with the PDGF signal operating over long distances to generally stimulate proliferation in an active axon fibre tract, while the glutamate signal is more spatially localised (due to efficient uptake by transporters) and inhibits proliferation when OPCs form a close apposition with an axon. If glutamate release from myelinated axons (Kriegler and Chiu, 1993) occurs from nodes of Ranvier, it might serve to tonically repress proliferation of OPCs, which have processes contacting the nodes (Butt et al., 1999) apparently in order to prevent axonal sprouting at that point (Huang et al., 2005). The glutamate released by action potentials may also regulate OPC migration (Wang et al., 1996; Gudz et al., 2006).

Blocking action potentials in axons (or conceivably in OPCs) reduces myelination of axons (Demerens et al., 1996). This may in part reflect the activity-evoked release of ATP and adenosine (Stevens et al., 2002; Ishibashi et al., 2006; Hamilton et al., 2008), but the presence of glutamatergic and GABAergic synapses onto OPCs (Bergles et al., 2000; Lin and Bergles, 2004; Jabs et al., 2005; Kukley et al., 2007; Ziskin et al., 2007; Káradóttir et al., 2005, 2008) suggests that synaptic contacts from unmyelinated axons to OPCs (and possibly production of action potentials in the OPCs) may play a key role in initiating myelination. 
Since synapses are made predominantly onto the $\mathrm{Na}^{+}$ channel expressing OPCs (Káradóttir et al., 2008), which can sense neural activity as a synaptic input, these cells might carry out a different type of myelination programme, that is regulated differently, from the ohmic OPCs that lack synaptic input and so do not sense neuronal activity in this way. Certainly neuronal activity is not always needed for myelination to occur, since under appropriate conditions oligodendrocytes can myelinate dead axons (Rosenberg et al., 2008). One possibility is that OPCs lacking voltage-gated $\mathrm{Na}^{+}$channels and synaptic input carry out a default myelination programme independent of neural activity, while OPCs expressing voltage-gated $\mathrm{Na}^{+}$channels and receiving synaptic input myelinate axons that are actively transmitting action potentials.

\section{THE DEVELDPMENTAL FATE DF THE TWD TYPES DF DPC}

In the white matter, OPCs develop into myelinating oligodendrocytes (Dimou et al., 2008; Rivers et al., 2008; Zhu et al., $2008 \mathrm{a}, \mathrm{b})$, with a small proportion remaining in the adult as adult OPCs. In the grey matter, however, some OPCs have also been reported to generate astrocytes (Dimou et al., 2008; Zhu et al., 2008a,b; Guo et al., 2009) and neurons (Rivers et al., 2008; Guo et al., 2009). Since mature oligodendrocytes and astrocytes essentially do not express detectable time- and voltage-gated conductances, while neurons express large voltage-gated $\mathrm{Na}^{+}$and $\mathrm{K}^{+}$currents, is it possible that it is the ohmic OPCs that develop into oligodendrocytes and astrocytes, while the $\mathrm{Na}^{+}$channel expressing OPCs develop into neurons or remain as adult OPCs? This seems unlikely, since in the white matter of the developing cerebellum and corpus callosum a snapshot at $\mathrm{P}_{7}$ reveals that about half of the OPCs express voltage-gated channels and half do not (Káradóttir et al., 2008). Thus, for the majority of cells derived from white matter OPCs (mainly oligodendrocytes) to lack significant voltage-gated conductances, as is the case, either the ohmic OPCs must divide at a far higher rate than the OPCs with voltage-gated channels or, more likely, both OPC classes can turn into oligodendrocytes and the OPCs expressing voltage-gated channels must lose the great majority of these channels in the process.

In the adult, OPCs comprise $2-3 \%$ of cells in the grey matter and $8-9 \%$ of cells in the white matter, and are the major proliferating cell class in the brain (Dawson et al., 2003). In the grey matter the OPCs may divide every 7 weeks (Rivers et al., 2008) so that, depending on the fraction of the dividing cells which differentiate into neurons and integrate successfully into the grey matter wiring, OPC-derived neurons could contribute significantly to adult neurogenesis. Extrapolating the data of Rivers et al. (2008), one can estimate that, each year, OPCs might add to the mouse piriform cortex a number of neurons equivalent to $2.4 \%$ of the neurons present. In addition to neurogenesis in the piriform cortex, Guo et al. (2009) have demonstrated that OPCs can generate neurons in the ventral forebrain, dorsal cerebal cortex and hippocampus. Assuming that this occurs in all grey matter regions, it would be interesting to calculate the total amount of adult neurogenesis from OPCs and compare it with the number of neurons generated from neuronal stem cells in the subventricular zone of the lateral ventricle and the hippocampal dentate gyrus.

\section{ACKNDWLEDGEMENTS}

This work was supported by the Wellcome Trust, the Royal Society, the MRC, the EU, the Central Research Fund of London University and Action Medical Research.

\section{REFERENCES}

Aguirre A.A., Chittajallu R., Belachew S. and Gallo V. (2004) $\mathrm{NG}_{2}$-expressing cells in the subventricular zone are type C-like cells and contribute to interneuron generation in the postnatal hippocampus. Journal of Cell Biology 165, 575-589.

Barres B.A. and Raff M.C. (1993) Proliferation of oligodendrocyte precursor cells depends on electrical activity in axons. Nature 361 , 258-260.

Belachew S., Yuan X. and Gallo V. (2001) Unraveling oligodendrocyte origin and function by cell-specific transgenesis. Developmental Neuroscience 23, 287-298.

Bergles D.E., Roberts J.D., Somogyi P. and Jahr C.E. (2000) Glutamatergic synapses on oligodendrocyte precursor cells in the hippocampus. Nature 405, 187-191.

Blankenfeld G.V., Verkhratsky A.N. and Kettenmann H. (1992) $\mathrm{Ca}^{2+}$ channel expression in the oligodendrocyte lineage. European Journal of Neuroscience 4, 1035-1048.

Borges K., Ohlemeyer C., Trotter J. and Kettenmann H. (1994) AMPA/ kainate receptor activation in murine oligodendrocyte precursor cells leads to activation of a cation conductance, calcium influx and blockade of delayed rectifying K+ channels. Neuroscience 63, 135-149.

Butt A.M., Duncan A., Hornby M.F., Kirvell S.L., Hunter A., Levine J.M. et al. (1999) Cells expressing the NG2 antigen contact nodes of Ranvier in adult CNS white matter. Glia 26, 84-91.

Chen H., Kintner D.B., Jones M., Matsuda T., Baba A., Kiedrowski L. et al. (2007) AMPA-mediated excitotoxicity in oligodendrocytes: role for $\mathrm{Na}^{+}-\mathrm{K}^{+}-\mathrm{Cl}^{-}$co-transport and reversal of $\mathrm{Na}^{+} / \mathrm{Ca}^{2+}$ exchanger. Journal of Neurochemistry 102, 1783-1795.

Chittajallu R., Aguirre A. and Gallo V. (2004) NG2-positive cells in the mouse white and grey matter display distinct physiological properties. Journal of Physiology 561, 109-122.

Clarke L., Hamilton N.B., Kessaris N., Richardson W.D. and Attwell D. (2009) The distribution of two types of oligodendrocyte precursor cell in different brain areas. Euroglia 2009 abstract, In Press.

Dawson M.R., Polito A., Levine J.M. and Reynolds R. (2003) NG2-expressing glial progenitor cells: an abundant and widespread population of cycling cells in the adult rat CNS. Molecular and Cellular Neuroscience 24, 476-488.

Demerens C., Stankoff B., Logak M., Anglade P., Allinquant B., Couraud F. et al. (1996) Induction of myelination in the central nervous system by electrical activity. Proceedings of the National Academy of Sciences of the U.S.A. 93, 9887-9892.

Dimou L., Simon C., Kirchhoff F., Takebayashi H. and Götz M. (2008) Progeny of Olig2-expressing progenitors in the gray and white matter of the adult mouse cerebral cortex. Journal of Neuroscience $28,10434-10442$

Ge W.P., Yang X.J., Zhang Z., Wang H.K., Shen W., Deng Q.D. et al. (2006) Long-term potentiation of neuron-glia synapses mediated by $\mathrm{Ca}^{2+}$-permeable AMPA receptors. Science 312, 1533-1537. 
Ge W.P., Zhou W., Luo Q., Jan L.Y. and Jan Y.N. (2008) Dividing glial cells maintain differentiated properties including complex morphology and functional synapses. Proceedings of the National Academy of Sciences of the U.S.A. 106, 328-333.

Gensert J.M. and Goldman J.E. (1997) Endogenous progenitors remyelinate demyelinated axons in the adult CNS. Neuron 19, 197-203.

Gudz T.I., Komuro H. and Macklin W.B. (2006) Glutamate stimulates oligodendrocyte progenitor migration mediated via an alpha $\mathrm{a}_{\mathrm{v}}$ integrin/myelin proteolipid protein complex. Journal of Neuroscience $26,2458-2466$.

Guo F., Ma J., McCauley E., Bannerman P. and Pleasure D. (2009) Early postnatal proteolipid promoter-expressing progenitors produce multilineage cells in vivo. Journal of Neuroscience 29, 7256-7270.

Hamilton N., Vayro S., Kirchhoff F., Verkhratsky A., Robbins J., Gorecki D.C. et al. (2008) Mechanisms of ATP- and glutamatemediated calcium signaling in white matter astrocytes. Glia 56, 734-749.

Häusser M. and Clark B.A. (1997) Tonic synaptic inhibition modulates neuronal output pattern and spatiotemporal synaptic integration. Neuron 19, 665-678.

Horner P.J., Power A.E., Kempermann G., Kuhn H.G., Palmer T.D., Winkler J. et al. (2000) Proliferation and differentiation of progenitor cells throughout the intact adult rat spinal cord. Journal of Neuroscience 20, 2218-2228.

Horner P.J., Thallmair M. and Gage F.H. (2002) Defining the NG2-expressing cell of the adult CNS. Journal of Neurocytology 31, 469-480.

Huang J.K., Phillips G.R., Roth A.D., Pedraza L., Shan W., Belkaid W. et al. (2005) Glial membranes at the node of Ranvier prevent neurite outgrowth. Science 310, 1813-1817.

Ishibashi T., Dakin K.A., Stevens B., Lee P.R., Kozlov S.V., Stewart C.L. et al. (2006) Astrocytes promote myelination in response to electrical impulses. Neuron 49, 823-832.

Jabs R., Pivneva T., Hüttmann K., Wyczynski A., Nolte C., Kettenmann H. et al. (2005) Synaptic transmission onto hippocampal glial cells with hGFAP promoter activity. Journal of Cell Science 118, 3791-3803.

Káradóttir R. and Attwell D. (2006) Combining patch-clamping of cells in brain slices with immunocytochemical labelling to define cell type and developmental stage. Nature Protocols 1, 1977-1986.

Káradóttir R., Cavelier P., Bergersen L. and Attwell D. (2005) NMDA receptors are expressed in oligodendrocytes and activated in ischaemia. Nature 438, 1162-1168.

Káradóttir R., Hamilton N.B., Bakiri Y. and Attwell D. (2008) Spiking and nonspiking classes of oligodendrocyte precursor glia in CNS white matter. Nature Neuroscience 11, 450-456.

Karram K., Goebbels S., Schwab M., Jennissen K., Seifert G., Steinhäuser C. et al. (2008) NG2-expressing cells in the nervous system revealed by the NG2-EYFP-knockin mouse. Genesis 46 , 743-757.

Keirstead H.S., Levine J.M. and Blakemore W. (1998) Response of the oligodendrocyte progenitor cell population (defined by NG2 labelling) to demyelination of the adult spinal cord. Glia 22, 161-170.

Kirischuk S., Scherer J., Möller T., Verkhratsky A. and Kettenmann H. (1995) Subcellular heterogeneity of voltage-gated $\mathrm{Ca}^{2+}$ channels in cells of the oligodendrocyte lineage. Glia 1, 1-12.

Knutson P., Ghiani C.A., Zhou J.M., Gallo V. and McBain C.J. (1997) $\mathrm{K}^{+}$channel expression and cell proliferation are regulated by intracellular sodium and membrane depolarization in oligodendrocyte progenitor cells. Journal of Neuroscience 17, 2669-2682.
Kriegler S. and Chiu S.Y. (1993) Calcium signaling of glial cells along mammalian axons. Journal of Neuroscience 13, 4229-4245.

Kukley M., Capetillo-Zarate E. and Dietrich D. (2007) Vesicular release of glutamate from axons in white matter. Nature Neuroscience 10, 311-320.

Kukley M., Kiladze M., Tognatta R., Hans M., Swandulla D., Schramm J. et al. (2008) Glial cells are born with synapses. FASEB Journal 22, 2957-2969.

Levine J.M. (1994) Increased expression of the NG2 chondroitin-sulfate proteoglycan after brain injury. Journal of Neuroscience 14, 4716-4730.

Levine J.M., Reynolds R. and Fawcett J.W. (2001) The oligodendrocyte precursor cell in health and disease. Trends in Neurosciences 24, 39-47.

Ligon K.L., Alberta J.A., Kho A.T., Weiss J., Kwaan M.R., Nutt C.L. et al. (2004) The oligodendroglial lineage marker Olig2 is universally expressed in diffuse gliomas. Journal of Neuropathology and Experimental Neurology 63, 499-509.

Ligon K.L., Kasari S., Kitada M., Sun T., Arnett H.A., Alberta J.A. et al. (2006) Developmental of NG2 neural progenitor cells requires Olig gene function. Proceedings of the National Academy of Sciences of the U.S.A. $103,7853-7858$.

Lin S.C. and Bergles D.E. (2004) Synaptic signaling between GABAergic interneurons and oligodendrocyte precursor cells in the hippocampus. Nature Neuroscience 7, 24-32.

LoTurco J.J., Owens D.F., Heath M.J., Davis M.B. and Kriegstein A.R (1995) GABA and glutamate depolarize cortical progenitor cells and inhibit DNA synthesis. Neuron 15, 1287-1298.

Lytle J.M., Chittajallu R., Wrathall J.R. and Gallo V. (2009) NG2 cell response in the CNP-EGFP mouse after contusive spinal cord injury. Glia 57, 270-285.

Mallon B.S., Shick H.E., Kidd G.J. and Macklin W.B. (2002) Proteolipid promoter activity distinguishes two populations of NG2-positive cells throughout neonatal cortical development. Journal of Neuroscience 22, $876-885$.

Matthias K., Kirchhoff F., Seifert G., Hüttmann K., Matyash M., Kettenmann H. et al. (2003) Segregated expression of AMPA-type glutamate receptors and glutamate transporters defines distinct astrocyte populations in the mouse hippocampus. Journal of Neuroscience 23, $1750-1758$.

McTigue D.M., Wei P. and Stokes B.T. (2001) Proliferation of $\mathrm{NG} 2$-positive cells and altered oligodendrocyte numbers in the contused rat spinal cord. Journal of Neuroscience 21, 3392-3400.

Moreno-Manzano V., Rodríguez-Jiménez F.J., García-Roselló M., Laínez S., Erceg S., Calvo M.T. et al. (2009) Activated spinal cord ependymal stem cells rescue neurological function. Stem Cells 27, 733-743.

Newell E.W. and Schlichter L.C. (2005) Integration of $\mathrm{K}^{+}$and $\mathrm{Cl}^{-}$currents regulate steady state and dynamic membrane potentials in cultured rat microglia. Journal of Physiology 567, 869-890.

Nishiyama A., Lin X.-H., Giese N., Heldin C.-H. and Stallcup W.B. (1996) Co-localization of NG2 proteoglycan and PDGF alpha receptor on $\mathrm{O}_{2} \mathrm{~A}$ progenitor cells in the developing rat brain. Journal of Neuroscience Research 43, 299-314.

Nishiyama A., Watanabe M., Yang Z. and Bu J. (2002) Identity, distribution, and development of polydendrocytes: $\mathrm{NG}_{2}$-expressing glial cells. Journal of Neurocytology 31, 437-455

Pringle N.P., Mudhar H.S., Collarini E.J. and Richardson W.D. (1992) PDGF receptors in the rat CNS: during late neurogenesis, PDGF alpha-receptor expression appears to be restricted to glial cells of the oligodendrocyte lineage. Development 115, 535-551. 
Rivers L.E., Young K.M., Rizzi M., Jamen F., Psachoulia K., Wade A. et al. (2008) PDGFRA/NG2 glia generate myelinating oligodendrocytes and piriform projection neurons in adult mice. Nature Neuroscience 11, 1392-1401.

Rosenberg S.S., Kelland E.E., Tokar E., De la Torre A.R. and Chan J.R. (2008) The geometric and spatial constraints of the microenvironment induce oligodendrocyte differentiation. Proceedings of the National Academy of Sciences of the U.S.A. 105, 14662-14667.

Schools G.P., Zhou M. and Kimelberg H.K. (2003) Electrophysiologically "complex" glial cells freshly isolated from the hippocampus are immunopositive for the chondroitin sulfate proteoglycan NG2. Journal of Neuroscience Research 73, 765-777.

Serrano A., Robitaille R. and Lacaille J.-C. (2008) Differential NMDA-dependent activation of glial cells in mouse hippocampus. Glia 56, 1648-1663.

Stallcup W.B. (2002) The NG2 proteoglycan: past insights and future prospects. Journal of Neurocytology 31, 423-435.

Stevens B., Porta S., Haak L.L., Gallo V. and Fields R.D. (2002) Adenosine: a neuron-glial transmitter promoting myelination in the CNS in response to action potentials. Neuron 36, 855-868.

Verkhratsky A.N., Trotter J. and Kettenmann H. (1990) Cultured glial precursor cells from mouse cortex express two types of calcium currents. Neuroscience Letters 112, 194-198.

Volpe J.J. (2001) Neurobiology of periventricular leukomalacia in the premature infant. Pediatric Research 50, 553-562.

Wang C., Pralong W.F., Schulz M.F., Rougon G., Aubry J.M., Pagliusi S. et al. (1996) Functional $N$-methyl-D-aspartate receptors in O-2A glial precursor cells: a critical role in regulating polysialic acid-neural cell adhesion molecule expression and cell migration. Journal of Cell Biology 135, 1565-1581.

Windrem M.S., Schanz S.J., Guo M., Tian G.F., Washco V., Stanwood N. et al. (2008) Neonatal chimerization with human glial progenitor cells can both remyelinate and rescue the otherwise lethally hypomyelinated shiverer mouse. Cell Stem Cell 2, 553-565.

Yuan X., Eisen A.M., McBain C.J. and Gallo V. (1998) A role for glutamate and its receptors in the regulation of oligodendrocyte development in cerebellar tissue slices. Development 125, 2901-2914.

Zhou M., Schools G.P. and Kimelberg H.K. (2000) GFAP mRNA positive glia acutely isolated from rat hippocampus predominantly show complex current patterns. Brain Research Molecular Brain Research $76,121-131$.

Zhu X., Bergles D.E. and Nishiyama A. (2008a) NG2 cells generate both oligodendrocytes and gray matter astrocytes. Development 135, 145-157.

Zhu X., Hill R.A. and Nishiyama A. (2008b) NG2 cells generate oligodendrocytes and gray matter astrocytes in the spinal cord. Neuron Glia Biology 4, 19-26.

Ziskin J.L., Nishiyama A., Rubio M., Fukaya M. and Bergles D.E. (2007) Vesicular release of glutamate from unmyelinated axons in white matter. Nature Neuroscience 10, 321-330.

\section{AUTHORS' ADDRESSES}

1 Department of Physiology

University College London

Gower St., London

WC1E 6BT

$\mathrm{UK}$

2 MRC Centre for Stem Cell and Regenerative Medicine

Cambridge Centre for Brain Repair and

Department of Veterinary Medicine

University of Cambridge

Madingley Road

Cambridge $\mathrm{CB}_{3}$ oES

UK

\section{Correspondence should be addressed to:}

David Attwell

Department of Physiology

University College London

Gower St., London

WC1E 6BT

UK

phone: $(+44)-20-7679-7342$

email: d.attwell@ucl.ac.uk 